\title{
MUTACIONES DEL PRESIDENCIALISMO \\ LA TRANSFORMACIÓN DEL PODER PRESIDENCIAL en Colombia (1974-2018)
}

\author{
Ana Catalina Arango Restrepo* \\ Institución Universitaria de Envigado \\ anacatalina.arango@derechoyjusticia.net
}

\begin{abstract}
RESUMEN: En la discusión sobre el desempeño de los sistemas presidenciales ha pasado desapercibida la gran capacidad de mutar que estos pueden desarrollar para resistirse a las reformas constitucionales que intentan reducir la concentración de poderes en cabeza del ejecutivo. A través de una descripción de las reformas aprobadas en Colombia entre 1974 y 2018, esta investigación pone en evidencia cómo éste consigue adaptarse a estos cambios para continuar ocupando una posición preponderante que le permite tomar las decisiones políticas más importantes, invadiendo e incluso anulando, las competencias y contrapesos ejercidos por el congreso y las demás instituciones. El análisis de este fenómeno puede ayudar a explicar por qué, pese a la variedad de reformas implementadas, no ha sido posible desplazar el sistema colombiano de un "biperpresidencialismo" hacia una forma moderada de presidencialismo, además de abrir una puerta para evaluar evidencias de este mismo fenómeno en los regímenes de la región.

ABSTRACT: The ability of presidential systems to mutate and resist constitutional reforms that reduce the concentration of executive powers has gone unnoticed in the discussion about the performance of these forms of government. Through a description of the constitutional reforms approved in Colombia between 1974 and 2018, this research shows how the executive manages to adapt to these changes to continue occupying a preponderant position that allows him to make the most important political decisions, invading and nullifying the competences and counterweights exercised by the other
\end{abstract}

* Doctora en Derecho y Magíster en Derecho Público por la Universidad Carlos III de Madrid (UC3M), España. Especialista en Derecho Constitucional y Parlamentario por la Universidad Externado de Colombia. Abogada de la Universidad Pontificia Bolivariana (Medellín). Docente de la Institución Universitaria de Envigado. Contacto: anacatalina.arango@derechoyjusticia.net. Número Orcid: https://orcid.org/00000001-8895-0702.

Una versión preliminar de este trabajo hace parte de la tesis doctoral Mutaciones del presidencialismo. La transformación del poder presidencial en Colombia (1974-2010), defendida en la Universidad Carlos III de Madrid y financiada por el Departamento Administrativo de Ciencia, Tecnología e Innovación de la República de Colombia (COLCIENCIAS), a través del Programa de Formación Doctoral en el Exterior (Convocatoria 617 de 2013).

Agradezco a Andrea Greppi, Roberto Gargarella y Julián Gaviria Mira sus valiosos comentarios que han enriquecido la versión inicial de este artículo.

Artículo recibido el 29 de julio de 2019 y aprobado el 6 de noviembre de 2019. 
institutions. The analysis of this phenomenon can help explain why it has not been possible to displace the Colombian system from a "hyper-presidentialism" towards a moderate form of presidentialism.

PALABRAS CLAVE: Hiperpresidencialismo, reformas constitucionales, mutaciones.

KEYWORDS: Hyper-presidentialism, constitutional reforms, mutations.

\section{INTRODUCCIÓN}

La discusión sobre el presidencialismo y sus formas "desviadas" sigue teniendo especial relevancia en América Latina en donde la expedición de nuevas constituciones ha sido insuficiente para revertir la tendencia que tienen estos regímenes a concentrar poderes en cabeza del ejecutivo. La aparición de caudillos que se perpetúan en el poder presentándose como la única solución viable a las crisis crónicas que enfrentan estos países, sigue siendo un problema recurrente. En efecto, en los últimos años, los presidentes en ejercicio de Venezuela, República Dominicana, Colombia, Bolivia y Ecuador impulsaron con éxito reformas constitucionales que les permitió reelegirse de forma inmediata y extender su mandato. Los presidentes de Argentina, Honduras y Costa Rica también movieron sus maquinarias para levantar la prohibición de reelección pero fracasaron en el intento. El de Costa Rica, sin embargo, se vio favorecido por una interpretación de la Corte que declaró inconstitucional el artículo que la prohibía. Los largos períodos en que estos presidentes retienen el poder les ha permitido ampliar su margen de decisión y desmontar las reformas que adelantó la región durante la tercera ola para moderar los poderes del ejecutivo y recuperar el papel del parlamento ${ }^{1}$. Del ejercicio de largos mandatos han resultado entonces viejas formas de presidencialismo que recuperan ciertos rasgos autoritarios pero escapan a la reprobación de los ciudadanos y la comunidad internacional porque continúan apelando a su "compromiso" con la democracia.

Estas formas de presidencialismo pueden encasillarse en la categoría de "hiperpresidencialismo" que en su momento acuñó Nino para referirse a sistemas, como el argentino, que se apartan del modelo norteamericano y se ubican "en el extremo del presidencialismo más acentuado" 2 . En esta forma de presidencialismo "todavía más exagerado", advierte Nino, el ejecutivo concentra un gran poder a partir de facultades, no sólo establecidas expresamente en la Constitución

1 Gargarella y Courtis (2009), pp. 28 y 29.

2 Nino (1990), p. 41. 
sino además ampliadas por las interpretaciones permisivas de los tribunales e incluso por circunstancias fácticas como la pérdida de peso del propio congreso y la rama judicial. Dentro de estas facultades el autor incluye la de designar a los miembros del gabinete $-\mathrm{y}$ de una gran cantidad de funcionarios que superan los que hacen parte de la administración- sin la intervención del parlamento, declarar el estado de sitio incluso cuando el congreso está en receso y sin control judicial, intervenir provincias bajo ciertas circunstancias, convocar al congreso a sesiones extraordinarias para debatir los temas que él fije, recibir delegación del congreso para ejercer facultades legislativas, expedir decretos de necesidad y urgencia y dirigir las Fuerzas Armadas y el Banco Central, entre otras ${ }^{3}$.

Tal concentración de poder, sin embargo, no se consigue exclusivamente a partir de las excesivas facultades que la Constitución o las prácticas políticas le otorgan al presidente para intervenir en el proceso de creación de la ley. La segunda fuente de poder del presidente sobre la que se construye un sistema "hiper" “ está determinada por el control que éste consiga de su propio partido en el congreso o de aquel que reúne la mayoría de escaños ${ }^{5}$. En efecto, estudios como los de García Montero demuestran que un ejecutivo con amplios poderes reconocidos en la Constitución pero sin una mayoría en el parlamento no puede ejercer un papel dominante sobre la actividad legislativa, a menos que logre construir coaliciones que resuelvan los problemas de fragmentación y polarización que puedan existir en él ${ }^{6}$. Se necesita así la confluencia de poderes legislativos y poderes partidistas ${ }^{7}$ para que el ejecutivo logre una supremacía sobre el parlamento que le permita imponer sus decisiones y ejercer un papel dominante sobre la actividad legislativa.

\footnotetext{
3 NinO (1990), pp. $41-43$.

4 Estudios sobre las condiciones que determinan la posición que ocupa el ejecutivo en el entramado institucional, pueden consultarse en: Loewenstein (1949), Shugart y Mainwaring, (1997), Lijphart (2000) y García Montero (2009).

5 Ver: Lijphart (2012), p. 127 y García Montero (2009).

6 García Montero (2009), pp. 264 y 265. Para medir los poderes partidistas, debe evaluarse cómo se articula el sistema electoral y de partidos: si éste favorece al presidente la consecución de una mayoría estable en él o si, por el contrario, incentiva la fragmentación y le exige formar coaliciones para obtener el respaldo de su agenda legislativa; si el sistema está o no polarizado, si favorece la disciplina de los partidos y cómo lo afecta la organización del calendario electoral

7 Shugart y Mainwaring (1997).
} 
De la intensidad entonces que adquiere cada uno de estos poderes en un sistema político concreto pueden resultar distintas formas de hiperpresidencialismo. Así, un sistema "hiper" puede construirse de forma preponderante sobre las facultades legislativas que la Constitución le otorga al presidente, sobre los poderes partidistas que éste logre a partir de una mayoría en el congreso o sobre ambos aspectos. Un sistema "hiper" puede moderarse si se recortan las facultades del ejecutivo y se restituye al parlamento la función legislativa, de manera que ésta es ejercida por él ${ }^{8}$. Algunos autores hablan incluso de una "atenuación" del presidencialismo 9 cuando se incorporan mecanismos propios de los sistemas parlamentarios que desdibujan el principio de separación de poderes y le permiten al ejecutivo enfrentarse con éxito a las presiones y bloqueos políticos que anteriormente se traducían en una quiebra de la democracia ${ }^{10}$.

Ahora bien, para hacer frente a los excesos de un ejecutivo con controles débiles se han impulsado en el caso colombiano diversas reformas constitucionales bajo el entendido de que las combinaciones institucionales "adecuadas" bastarían para moderar el ejercicio del poder presidencial y garantizar la estabilidad de la democracia ${ }^{11}$. Estas medidas han ido desde reducir las facultades legislativas del presidente y dotar a las demás instituciones de nuevas herramientas para ejercer un contrapeso efectivo sobre él, hasta la reforma al sistema electoral y de partidos que reduciría la fragmentación y favorecería su disciplina interna. La especialización de estos instrumentos legales puede llevar al equívoco de suponer que, si bien la Constitución de 1886 había creado las bases de un sistema hiperpresidencial, éste empieza a moderarse con la Constitución de 1991 e incluso se atenúa con la incorporación que hizo el Acto Legislativo de 2003 de figuras propias de los sistemas parlamentarios. No obstante, un estudio detenido del caso pone en evidencia que ambas reformas fueron insuficientes para impedir que el ejecutivo continuara concentrando fuertes poderes. Esta disociación entre los cambios constitucionales y el ejercicio del poder presidencial plantea la pregunta que sirve como punto de partida a esta investigación: ¿por qué cada vez que se identifica la "brecha" por la que el poder

8 Un estudio de las variaciones que puede experimentar el sistema presidencial ("hiperpresidencialismo", presidencialismo "moderado" y presidencialismo "atenuado") puede consultarse en ARANGO RestrePO (2018).

9 Nino (2003), p. 241 y Loewenstein (1949), p. 454.

10 Marsteintredet (2008), pp. 36 y 37.

11 Mainwaring y Shugart (1997), p. 469. 
presidencial se desborda y se crea el "cerco institucional" para contenerlo, el ejecutivo logra abrirse un nuevo espacio que le permite seguirse imponiendo sobre las demás ramas?

Para responder a esta pregunta este trabajo parte de la hipótesis de que el sistema presidencial desarrolla una gran capacidad de mutar que le permite resistirse a las reformas constitucionales que intentan reducir la concentración de poderes en cabeza del ejecutivo. A diferencia del concepto "mutación constitucional" -que se ha utilizado para referirse a "la modificación que deja indemne su texto sin cambiarlo formalmente que se produce por hechos que no tienen que ir acompañados por la intención, o conciencia, de tal mutación"12 - con el término "mutación del presidencialismo" quiero hacer referencia al fenómeno según el cual cada vez que el constituyente lleva a cabo una modificación del texto constitucional que modera el ejercicio del poder presidencial, el ejecutivo consigue adaptarse a dicha reforma para recuperar su lugar dentro del sistema. El problema entonces no es la "modificación informal" de la Constitución. Por el contrario, la capacidad del presidencialismo de mutar se reconoce porque el presidente se ciñe a los límites expresos que el legislador le impone pero utiliza otras estrategias para ganar el espacio que ha perdido para imponerse sobre los demás poderes.

El estudio de las mutaciones que experimenta el sistema presidencial colombiano comprende un tramo de la historia constitucional y política del país que empieza el 7 de agosto de 1974 -fecha en la que termina el mandato presidencial de Misael Pastrana Borrero y con éste, el pacto entre liberales y conservadores que dio origen al Frente Nacional-y termina el 6 de agosto de 2018, fecha en que concluye el período de Juan Manuel Santos. Con el fin de identificar cómo se comporta el ejecutivo cuando se implementa una reforma constitucional que intenta reducir las facultades legislativas o los poderes partidistas del ejecutivo, se han dividido estos cuarenta y cuatro años en tres segmentos atendiendo a dos acontecimientos que modifican profundamente el ejercicio del poder presidencial y marcan puntos de cierre e inicio de nuevas etapas en la historia constitucional colombiana: la expedición de la Carta de 1991 y la reforma política de 2003.

12 Jellinek (1991), p. 7. 


\section{LA CONFIGURACIÓN DEL UN SISTEMA HIPERPRESIDENCIAL BAJO la Constitución de 1886 (período 1: 1974-1990)13}

En este período el sistema político adquiere los rasgos propios del hiperpresidencialismo en la medida en que de los arreglos institucionales y la práctica política resulta la supremacía del poder presidencial sobre los demás órganos del Estado porque se concentran las funciones ejecutiva y legislativa en cabeza suya, de manera que el parlamento queda estrictamente subordinado a él14. La concentración de la función ejecutiva y legislativa en cabeza del presidente se consigue, de un lado, a partir de las excesivas facultades que le otorgó la Constitución de intervenir en el proceso de creación de la ley, a través de poderes proactivos y reactivos ${ }^{15}$, y de otro, de los amplios poderes partidistas que construye a partir de la mayoría que consigue su partido en el congreso y de la escasa oposición que encuentra en él ${ }^{16}$.

Para empezar, al presidente, como máxima autoridad administrativa, se le otorgó la facultad de nombrar, directamente o través de sus subalternos, casi la totalidad de la plantilla del Estado ${ }^{17}$. El presidente entonces era "dueño de la nómina oficial" 18 y como tal, designaba a las cabezas de los cargos políticos -tanto de las entidades territoriales (gobernadores que a su vez designaban alcaldes) como de las entidades descentralizadas- y, además, ratificaba o hacía cambios en el resto de la administración pública. Era quien, "[r] epartía salarios, permisos, exenciones, subsidios, ganancias, privilegios, contratos; en pocas pa-

13 Durante este lapso ocupan la presidencia, de forma consecutiva y por períodos de cuatro años, Alfonso López Michelsen, Julio Cesar Turbay, Belisario Betancur y Virgilio Barco. La fecha que se utiliza como punto de partida pone término al Frente Nacional y con él, a un período de democracia que algunos denominan "oligárquica", "consociacional", "restringida" o "bajo asalto" WiLdE (1978), p. 34, SÁCHICA (1970), p. 30. La segunda fecha cierra el ciclo de la Constitución de 1886 y con él, una primera modalidad de presidencialismo que no volverá a repetirse en los períodos siguientes.

14 Arango Restrepo (2018), p. 254.

15 Shugart y Mainwaring (1997), p. 41.

16 García Montero (2009).

17 La facultad que tenía el presidente de la República de nombrar ministros y gobernadores se extendió, a partir de la reforma de 1968, a los jefes de Departamentos Administrativos y a los directores o gerentes de establecimientos públicos descentralizados (artículo 41 numerales 1 y 5 del Acto legislativo 1 de 1968). Se eliminaron así los mecanismos que les asignaba su elección a las juntas directivas de dichas entidades en cuya composición participaban corporaciones o gremios. Ver: URIBE (1977), p. 272.

18 VÁzQuez (1986), p. III. 
labras, oportunidades que no se podían encontrar en ningún otro sitio"19. La presidencia era así el botín de los partidos políticos y aquel que la conseguía repartía los recursos estatales entre sus miembros, desde la cúspide hasta la base.

Junto a este poder nominador, al presidente se le otorgó la facultad de expedir decretos con fuerza de ley que le permitieron modificar el statu quo de forma unilateral y asumir de forma preponderante el ejercicio de la función legislativa ${ }^{20}$. En primer lugar, la delegación de facultades extraordinarias que de forma reiterada le hizo el congreso le permitió no sólo sobrepasar la función legislativa ejercida por el propio parlamento sino sobre aquellas materias que por su importancia corresponden de forma exclusiva a éste. Fue así como el presidente llegó al punto de expedir códigos en materia penal, procesal civil, comercial, contenciosa administrativa, electoral y policial, entre otras. En segundo lugar, con las continuas declaratorias de un estado de excepción, que llevaron a que éste fuera casi permanente ${ }^{21}$, el presidente pudo legislar sobre asuntos que no siempre guardaban conexión con la perturbación que justificaba su declaratoria e incluso, los decretos legislativos se seguían aplicando una vez se había levantado el estado de excepción o el ejecutivo se negaba a levantarlo hasta tanto el congreso no los integrara a la legislación ordinaria ${ }^{22}$. Los excesos del ejecutivo fueron permitidos por la Corte Suprema quien se negó a ejercer un control material de los decretos legislativos defendiendo, o bien la imposibilidad de llevar a cabo cualquier forma de control sobre ellos o bien, afirmando que su competencia se reducía a un control de carácter estrictamente formal ${ }^{23}$. Así, sus

19 WiLde (1989), p. 40.

20 Si se toman los decretos con fuerza de ley expedidos en este período, se tiene que el ejecutivo sobrepasa la función legislativa ejercida por el congreso en un $16.9 \%$ pues, mientras el presidente expide 1.455 decretos con fuerza de ley, el congreso aprueba 1.209 leyes. Ver: Arango Restrepo (2017).

21 De hecho "en los 21 años transcurridos entre 1970 y 1991, Colombia vivió 206 meses bajo estado de excepción, es decir, 17 años, lo cual representa el 82\% del tiempo transcurrido". Ver: GarCía y UprimnY (2005), p. 7.

22 García (2001), p. 333, se refiere a esta estrategia como el "blanqueo". Un caso emblemático es la incorporación en el Código Penal de algunas medidas adoptadas en el Estatuto de Seguridad de Julio Cesar Turbay como, por ejemplo, la extensión de la competencia de la jurisdicción militar para juzgar la comisión de determinados delitos por parte de civiles. Ver: ArCher y Chernick (1989), p. 42.

23 Ariza y Barreto (2001), p. 156. Ver, por ejemplo, Corte Suprema de Justicia de Colombia, sentencia D1970 del 15 de octubre de 1974. En esta sentencia la Corte revisa la constitucionalidad del decreto 1970 de 1974, a través del cual el presidente López Michelsen decretaba un estado de emergencia económica. 
fallos legitimaron la utilización desmedida del estado de sitio declarando la exequibilidad de sus decretos y limitándose a revisar la legalidad del procedimiento, en lugar de su contenido ${ }^{24}$. A estas facultades que adquiría el presidente durante los estados de excepción debe sumarse la "retención". Otra herramienta con la que contó el gobierno para prevenir y reprimir el desorden y que lo autorizaba para que -aun en tiempos de paz, pero habiendo "graves motivos para temer perturbación del orden público"- aprehendiera y retuviera a aquellas personas contra las que hubiera "graves indicios de que atentaban contra la paz pública" 25 . Esta medida consagraba dos supuestos en los que podía encajarse un sinnúmero de conductas que facilitaba una utilización abusiva por parte del gobierno ${ }^{26}$.

Pero no sólo el presidente contaba con amplias facultades para intervenir en el proceso de creación de la ley. También estuvo acompañado por un congreso que la reforma de 1968 había terminado de "anular" como órgano máximo de deliberación y decisión. En efecto, esta reforma constitucional transfirió al ejecutivo parte de las competencias propias del congreso, desestructurando el sistema de frenos y contrapesos y convirtiéndolo en un órgano dependiente del ejecutivo frente al cual únicamente conservaba una competencia residual: la de afirmar o negar sus proposiciones. Así, sobre un amplísimo número de materias de carácter económico, presupuestario, fiscal y monetario "que cubren la casi totalidad de las funciones del Estado moderno"27, el ejecutivo asumió la iniciativa legislativa exclusiva de aquellos proyectos tendientes a crearlas o reformarlas ${ }^{28}$. De esta forma el gobierno ya no ejerce funciones de naturaleza estrictamente administrativa, pues, no solo ejecuta una política, sino que además la formula y la dirige.

\footnotetext{
${ }^{24}$ Un estudio de la jurisprudencia de la Corte Suprema de Justicia respecto a las facultades del ejecutivo durante los estados de sitio y su tendencia a inclinar la balanza a favor del ejecutivo, a quien entendía como "el guardián supremo del orden público", puede consultarse en: BARreto (2012), pp. 15-26.

25 Constitución Política de Colombia, inciso 2 del artículo 28.

26 SÁCHICA (1970), p. 42. Esta medida, peligrosa por su amplitud e indeterminación, fue limitada más no suprimida por la reforma de 1968 y estableció un término de diez días para que el gobierno consiguiera las pruebas que justificaban la retención, vencido el cual el retenido debía ser liberado o puesto a disposición del juez competente.

27 Yepes (1974), p. 159.

28 Estas materias están contempladas en los ordinales 3, 4, 9 y 22 del artículo 11 del Acto legislativo 1 de 1968, que modifica el artículo 79 de la Constitución Política de Colombia de 1886 y parágrafo 2 del artículo 13 del mismo Acto legislativo, que modifica el artículo 79.
} 
Restringida la iniciativa parlamentaria en todas las materias relacionadas con el gasto público, el congreso conservó la potestad de introducir las modificaciones que acordaran e impulsar los demás proyectos de ley que se referían a asuntos de menor importancia. Conviene advertir, sin embargo, que el artículo 211 consagró tales restricciones a su facultad para introducir modificaciones a los proyectos de iniciativa gubernamental, que ésta resultó casi nula. Para compensar a un congreso desprovisto de funciones, la reforma le concedió un papel de vigilancia sobre algunas actuaciones del ejecutivo que llevaría a cabo a través de una Comisión Especial Permanente ${ }^{29}$. No obstante, tampoco esta Comisión llegaría a conformarse, "[e]l resultado es la omnipotencia del presidente para hacer y deshacer los planes económicos y sociales"30. De forma que algunos autores afirmaron que "[d]espués de la reforma de 1968 se puede gobernar en Colombia sin Congreso, y aún contra el Congreso, sin que la administración sufra menoscabo ni se amenace la estabilidad del régimen" 31 .

El replanteamiento institucional que supuso la reforma de 1968 produjo a su vez un cambio en la dinámica electoral. Las elecciones que antes enfrentaban a dos partidos que apelaban a ideologías contrarias, pasó a oponer a un gran número de elites emergentes que controlaban pequeñas porciones del electorado y competían dentro de un mismo partido por acceder a los recursos controlados por el ejecutivo ${ }^{32}$. Así, este congreso conformado por facciones particularistas cede al presidente la facultad de trazar las políticas nacionales ${ }^{33}$ y se conforma con ver reducido su papel a poco más que el de un lobista que vela por satisfacer

29 Vigilar la ejecución de los planes y programas de desarrollo económico y social y la evolución del gasto público (artículo 14 del Acto legislativo 1 de 1968 que modifica el artículo 80 de la Constitución Política de Colombia).

30 VÁzquez (1986), p. 420.

31 Uribe (1977), p. 270.

32 ARCHER (1995), pp. 178 y 179.

33 No quiere decir esto que el congreso no tuviera ninguna preocupación por decidir sobre políticas nacionales, como mínimo debía aprobar aquellas que le permitieran atraer el voto urbano que aseguraría su victoria en las elecciones presidenciales. De igual forma, las iniciativas reformistas de un presidente que representa a un electorado urbano pueden encontrar respaldo en un congreso que responde a clientelas regionales cuando dichas propuestas permiten convertir los recursos públicos en beneficios particulares bajo su control. ARCHER y ShUGART (1997), pp. 144 y 145, ponen como ejemplo dos propuestas exitosas de las administraciones de Betancur y Barco: la elección directa de alcaldes y el proceso de descentralización administrativa. 
las demandas de la clientela que respalda su elección y asegura su continuidad ${ }^{34}$. En esta dinámica, el congresista se dedica a crear y conservar un capital político que asegura su permanencia en el congreso y que, a su vez, le exige la consecución de recursos económicos suficientes para sufragar las campañas electorales e invertir en las regiones o localidades que aseguran la fidelidad de su nicho electoral. Esta fidelidad se consiguió a través de recursos de carácter institucional como los "auxilios parlamentarios" pero también con el manejo arbitrario de las nóminas estatal y regional, del tráfico de influencias en las inversiones del Estado e incluso, en la compra de votos a granel ${ }^{35}$.

La nueva posición del congreso facilitó al ejecutivo la construcción de amplios poderes partidistas que le permitieron conseguir la aprobación de su agenda y evadir el control que sobre él estaba llamado a ejercer el parlamento ${ }^{36}$. Estos poderes se construyen en los primeros dos mandatos (Alfonso López y Julio César Turbay) a partir de la mayoría de curules que obtiene el partido del presidente, tanto en Cámara como en Senado pues, los partidos tradicionales reciben casi la totalidad de los votos: "el partido Liberal recibió 55.6 por ciento de los votos de la Cámara en 1974, 55.1 por ciento en 1978, 56.3 por ciento en 1982, y 54.2 por ciento en 1986; el partido Conservador obtuvo 32 por ciento en 1974, 39.4 por ciento en 1978 y 40.3 por ciento en 1982"37. La izquierda, aunque sirvió para elegir ocasionalmente miembros del congreso, asambleas departamentales y concejos municipales, resultó insuficiente hasta 1986 para conseguir más de un 5 por ciento del voto nacional en una elección de presidente o congreso ${ }^{38}$. Cuando el partido del presidente no consiguió la mayoría de curules en el parlamento, los poderes partidistas se construyeron a partir de la formación de coaliciones que les permitió gobernar, aunque no sin tropiezos, al menos sí con suficiente margen como para sacar adelante su agenda.

La construcción de estas coaliciones estuvo influenciada por la dinámica establecida por el Frente Nacional. A pesar de que el pacto de alternación presidencial termina con la elección de López Michelsen en 1974, la reforma de 1968 había

\footnotetext{
34 Shugart y Carey (1992), p. 184.

35 Leal y Dávila (1990), pp. 71-80.

36 Estando compuesta la Cámara por 199 escaños, la mayoría absoluta la consigue un partido si elige 100 representantes. Por su parte, el Senado, compuesto por 114 escaños, necesita la elección de 58 senadores.

37 Hoskin (1988), p. 49.

38 Dix (1987), p. 106.
} 
previsto que la paridad burocrática continuaría hasta las elecciones presidenciales de 1978. A partir de este año y con el objeto de preservar "el espíritu nacional en la rama ejecutiva y en la administración pública", la Constitución dispuso que el nombramiento de los ministros y demás cargos de la administración debía hacerse de forma tal que diera "participación adecuada y equitativa al partido mayoritario distinto al del presidente de la República" 39 . Si se tiene en cuenta que entre un ochenta y un noventa por ciento del congreso era ocupado por los partidos tradicionales y que éstos compartían el poder desde 1958, la condición de buscar el apoyo de la segunda fuerza y de compartir con ella el gobierno, hace que la existencia de un verdadero partido de oposición pierda sentido. De esta forma, "un Frente Nacional de hecho remplaza un Frente Nacional de derecho" 40 . Sumado a esto, la ausencia de oposición puede explicarse en la represión contaste de que fueron víctimas las terceras fuerzas por parte del gobierno y que incluye el exterminio físico de la totalidad de un partido que empezaba a perfilarse como una fuerza importante de oposición, la Unión Patriótica, en el que quedó probada la participación tanto de políticos como de miembros de las Fuerzas Armadas ${ }^{41}$, y de cuyo silenciamiento se beneficiaron el gobierno y los partidos tradicionales ${ }^{42}$.

Así las cosas, en este período el sistema adquiere todos los rasgos propios del hiperpresidencialismo. El ejecutivo cuenta con un gran poder nominador, excesivos poderes legislativos que resultan de su facultad de modificar el statu quo de forma unilateral a través de los decretos con fuerza de ley, de vetar los proyectos de ley exigiéndole al congreso una mayoría calificada para rechazar dicho veto y de la iniciativa legislativa exclusiva sobre un gran número de materias. A esto se suman los amplios poderes partidistas que surgen de la mayoría de escaños que consigue el partido del presidente en el congreso y de la imposibilidad de cualquier partido de ejercer una oposición real al gobierno.

39 Constitución Política de Colombia, artículo 120.

40 Pécaut (1989), p. 315.

41 Ver, por ejemplo, la condena al ex senador Cesar Pérez García a treinta años de prisión por su actuación, en calidad de determinador, en la masacre de Segovia (Antioquia) en la que 45 personas fueron asesinadas y 8 más sufrieron lesiones personales. Corte Suprema de Justicia de Colombia, Sala de Casación Penal, sentencia del 15 de mayo de 2013, proceso No 33118.

42 El exterminio de todo este partido político de izquierda supuso "además de la eliminación física de 3.500 personas, la expulsión del escenario político de una fuerza política nacional”. Ver: Medina (1997), p. 62. 


\section{PRIMERA MUTACIÓN DEL SISTEMA PRESIDENCIAL: EL PASO A LA}

CONSTITUCIÓN DE 1991 (PERÍOdo 2: 1990- 2002)43

Los rasgos que adquiere el presidencialismo a partir de 1991 sufren una transformación que en gran medida puede explicarse en la expedición de una nueva Constitución. A diferencia del período anterior (1974-1990), la Carta de 1991 intenta restablecer el equilibrio de poderes, de manera que si en éste se configura una nueva modalidad de hiperpresidencialismo ya no puede atribuirse exclusivamente al diseño institucional sino a una reacomodación de los actores políticos a las nuevas reglas de juego. El poder nominador del presidente, que ya había sido recortado con la elección popular de alcaldes aprobada en 1986, se limitó aún más sustrayendo como cargos de su libre nombramiento y remoción a los gobernadores y al Procurador General de la Nación. Respecto a este último, le corresponde al Senado su elección de terna presentada por el presidente. Se estableció la segunda vuelta para la elección del presidente, se prohibió su reelección y el vicepresidente pasó a ser elegido por voto popular.

También las facultades legislativas del presidente sufren una importante reducción. Por un lado, los estados de excepción son objeto de serias limitaciones con la especificación de los supuestos que pueden dar lugar a su declaratoria, las facultades que adquiere el presidente y el tiempo durante el cual puede hacer uso de ellas ${ }^{44}$. Para obligar al gobierno a sujetarse a los nuevos límites fue determinante el control ejercido por la Corte Constitucional, cuya intervención, a diferencia de la llevada a cabo por la Corte Suprema bajo la vigencia de la

43 Este período empieza con la posesión de Cesar Gaviria el 7 de agosto de 1990 y termina con el período de Andrés Pastrana, el 6 de agosto de 2002. En estos 12 años ejercen la presidencia, de forma consecutiva y por períodos de cuatro años, Cesar Gaviria, Ernesto Samper y Andrés Pastrana. La fecha de apertura atiende a la expedición de una nueva Constitución que supuso la reconfiguración de las condiciones jurídicas y políticas a partir de las cuales el presidente puede gobernar. La fecha de corte responde a la expedición de una reforma política en el año 2003 que cambia una vez más el funcionamiento del sistema electoral y de partidos y con éste, el ejercicio del poder presidencial. Teniendo en cuenta que para la fecha de la reforma el presidente Álvaro Uribe solo llevaría un año de mandato, se decidió hacer el corte en 2002 con la terminación del mandato de Andrés Pastrana.

44 El estado de emergencia se conservó y estado de sitio se diferenció en dos supuestos: guerra exterior y conmoción interior. Uno de los grandes aciertos del constituyente de 1991 fue extender a la conmoción interior el carácter temporal que la reforma de 1968 le había asignado al estado de emergencia económica. Dentro de los límites impuestos a los estados de excepción vale la pena mencionar la prohibición expresa de que los civiles sean investigados y juzgados por la justicia militar. De igual forma, en adelante no pueden suspender los derechos humanos ni las libertades fundamentales ni tampoco interrumpir el normal funcionamiento de las ramas del poder público o de los órganos del Estado. 
Constitución de 1886, supuso "un verdadero contrapeso al ejecutivo" 45 . Así, cuando los presidentes Cesar Gaviria y Ernesto Samper intentaron continuar con la dinámica de utilizar los estados de excepción para impulsar su agenda de gobierno mediante decreto ${ }^{46}$, la Corte Constitucional los obligó a enfrentar las crisis sin saltarse al congreso. El presidente no tuvo entonces otra opción que gobernar la mayor parte del tiempo con las herramientas que son propias a un estado de normalidad.

Por otro lado, la delegación de facultades extraordinarias es sometida a nuevos límites que suponen la reducción de las materias y los tiempos en los que el congreso puede revestir al ejecutivo de facultades para legislar ${ }^{47}$. Con estas restricciones el constituyente se propuso revertir la tendencia del legislativo a delegar en exceso sus funciones en el ejecutivo y forzarlo a ocuparse de nuevo de los asuntos legislativos que por derecho le corresponden ${ }^{48}$. Además, si bajo la Constitución de 1886 el presidente tenía cierta preeminencia sobre el parlamento porque podía expedir decretos ley sin que estuviera expresa la facultad del congreso de modificarlos o derogarlos ${ }^{49}$, con la nueva Carta éste recupera la facultad de modificar "en todo tiempo y por iniciativa propia", dichos decretos ${ }^{50}$.

Respecto a la iniciativa legislativa exclusiva, la Constitución redujo la facultad que tenía el ejecutivo de incidir sobre el proceso de creación de la ley. El congreso recuperó la facultad de presentar proyectos de ley sobre una gran variedad de materias y respecto de aquellos que continuaron siendo de iniciativa legislativa

45 García y Uprimny (2005), p. 13. Sobre este punto advierten los autores "sólo el 9\% de los decretos de estado de sitio fueron anulados entre 1984 y 1991, mientras que el 34\% de los decretos de conmoción interior fueron declarados inconstitucionales entre 1992 y 1996".

46 Cesar Gaviria declaró, cuando ya había entrado en vigencia la Constitución de 1991, el estado de excepción seis veces y en casi todas sus modalidades: emergencia económica, emergencia social, emergencia por grave calamidad pública y conmoción interior. A partir del gobierno de Ernesto Samper, estos empiezan a reducirse pasando a dos declaratorias de conmoción interior y una emergencia económica, precisamente por los controles ejercidos por la Corte Constitucional.

47 En adelante, la delegación de facultades extraordinarias sólo puede hacerse a partir de una solicitud expresa por parte del gobierno para un período máximo de seis meses y para los temas precisos para los que el presidente pide dicha facultad. Además, su aprobación exige la mayoría absoluta de los miembros de ambas cámaras (ya no la mayoría del quórum) y en ningún caso puede conferirse para expedir códigos, leyes estatutarias u orgánicas, crear servicios administrativos y técnicos de las cámaras o decretar impuestos.

48 ArCher y Shugart (1997), pp. 122 y 123.

49 Constitución Política de Colombia, artículo 76 Núm. 10.

50 Constitución Política de Colombia, artículo 150 Núm. 10. 
exclusiva del gobierno, se le otorgó la facultad de introducir las modificaciones que considerara pertinentes sin las restricciones que en la Constitución de 1886 habían hecho inviable su participación. En cuanto a la facultad de vetar la ley, se eliminó la mayoría calificada que se exigía a ambas cámaras para rechazar las objeciones presidenciales ${ }^{51}$ y se estableció un veto "relativamente" débil que puede ser sobrepasado, en cualquier caso, por la mayoría de los miembros de cada cámara ${ }^{52}$. Por último, el poder nominador del presidente -reducido con la reforma de 1986 que estableció la elección popular alcaldes- se limitó aún más sustrayendo como cargos de su libre nombramiento y remoción a los gobernadores y al Procurador General de la Nación.

La reducción de las facultades legislativas estuvo acompañada por el diseño de un sistema electoral y de partidos que no favorecía la construcción de fuertes poderes partidistas ${ }^{53}$. Con el fin de facilitar la participación y acceso de nuevas fuerzas políticas excluidas de la contienda electoral, el sistema electoral se flexibilizó y eliminó prácticamente todas las barreras para que minorías étnicas, políticas y religiosas e incluso grupos armados en proceso de desmovilización pudieran ingresar ${ }^{54}$. Esta apertura permitió la expresión de fuerzas que estaban al margen de la toma de decisiones exacerbando el faccionalismo y aunque éste dio la sensación de que acabaría con el bipartidismo, terminó por volverse en contra de las terceras fuerzas que empezaban a consolidarse ${ }^{55}$. El faccionalismo entonces tuvo el problema de acabar con los pequeños partidos ${ }^{56}$ y de minar la

51 Constitución Política de Colombia, artículo 88.

52 Archer y Shugart (1997), pp. 119 y 120.

53 La Constitución Política de Colombia de 1991 continuó con el sistema de representación proporcional y la fórmula electoral de "Hare" establecida en la Constitución de 1886. El problema de esta fórmula es que favorece la "guerra de residuos" porque cada partido multiplica sus listas con el fin de sacar el mayor número de curules apostándole a los altos residuos en lugar de a altas votaciones. Ver: Bejarano y Pizarro (2005), p. 246.

54 La eliminación de estas barreras incluye la financiación con fondos públicos de las actividades y campañas electorales de los partidos y movimientos que tuvieran personería jurídica o representación en el congreso. A esto se añaden dos elementos que venían de la Constitución de 1886: la posibilidad de que cada partido presente múltiples listas cerradas y bloqueadas en cada distrito electoral y la inexistencia de umbrales electorales que permitía a cualquier partido acceder al congreso sin necesidad de que conseguir un mínimo de votos.

55 Pizarro (1997), pp. 97 y 98.

56 La Alianza Democrática M-19 fue la tercera fuerza en las elecciones presidenciales de 1990, la segunda en la Asamblea Constituyente y la tercera en el Congreso de 1991. No obstante, pasó a no ocupar ninguna curul en el Senado y apenas dos en la Cámara en 1994 y en 1998 ya habría desaparecido. Pizarro 
disciplina interna de los más fuertes para que actuaran como un cuerpo cohesionado. A su vez, la falta de cohesión interna tuvo el doble efecto de debilitar, por un lado, al congreso que era susceptible a las presiones del ejecutivo y, por otro, al mismo ejecutivo, que no tenía fácil la tarea de gobernar sin un apoyo estable en el parlamento ${ }^{57}$. Incluso la oposición resultó afectada con una fragmentación excesiva pues tuvo dificultades para trazar una posición coherente que le permitiera controlar al gobierno y presentarse como una verdadera alternativa política.

Adicional a la fragmentación del sistema de partidos, la debilidad de los poderes partidistas del presidente se explica en la estrecha mayoría que consigue su partido en el congreso durante los gobiernos de Cesar Gaviria y Ernesto Samper y en la falta de cualquier tipo de mayoría en el caso de Andrés Pastrana. Y si en un sistema de partidos disciplinados a un presidente le basta con esta mayoría para gobernar, la indisciplina de los mismos y la exacerbación de la fragmentación, le impiden en este período controlarla y apoyarse exclusivamente en ella. $\mathrm{Al}$ no poder contar con una mayoría estable, el presidente se enfrenta a presiones y chantajes constantes por parte de congresistas que condicionan su voto a las ventajas que puedan obtener para mantener su influencia, cultivar su electorado o ascender en su carrera política. De esta forma, el presidente gobierna "asediado por el poder legislativo" 58 .

Con facultades legislativas moderadas y poderes partidistas reducidos, el ejecutivo tiene limitada su capacidad tanto para actuar de forma unilateral como para imponerse sobre el congreso. Pero, aunque la erosión de ambos poderes puede parecer en un principio suficiente para conseguir una "moderación" del hiperpresidencialismo, en este punto el sistema pone en evidencia su gran capacidad para mutar. En efecto, utilizando a su favor la altísima fragmentación en que degeneró el sistema de partidos y la indisciplina de los mismos, el ejecutivo se adapta a las nuevas condiciones y se vale de herramientas "transaccionales"59

(1997), pp. 97 y 98, atribuye en gran parte su colapso y desaparición al uso que hizo el partido de la “operación avispa”.

57 UnGaR (1998), p. 187.

58 Duque (2014), p. 106.

59 DuQUe (2014), p. 117. Si bien para Duque el caso colombiano encaja en la categoría de presidencialismo "moderado" por los débiles poderes partidistas que tiene el presidente para conseguir el respaldo del congreso, difiero con el autor en la medida en que considero que esa debilidad es compensada precisamente con la dinámica "transaccional" que él identifica como el elemento que modera su fuerza excesiva. 
que le permiten negociar individualmente con los congresistas la aprobación de su programa de gobierno. Pese a la gran reducción del poder nominador que supuso la Constitución de 1991, el presidente siguió contando con una variedad de instrumentos para construir sus mayorías como los recursos del presupuesto nacional que se distribuyeron entre los congresistas en forma de "auxilios parlamentarios" -con la Constitución de 1991 pasaron a llamarse "cupos indicativos" o "recursos de inversión social regional"- así como el nombramiento en cargos de burocracia como embajadas, consulados y demás entidades del Estado en los que la carrera administrativa seguía siendo débil ${ }^{60}$.

La debilidad del partido del presidente también supuso un "punto de inflexión" en la forma en que funcionaba el mismo congreso antes de la expedición de la Constitución de 1991. Gutiérrez se refiere a él como "un nuevo equilibrio estable" en el que las terceras fuerzas son neutralizadas por el partido ganador ${ }^{61}$. En este sentido, advierte, si con anterioridad el voto de las tercerías funcionaba simplemente como una constancia y si pactaban lo hacían con el segundo partido "para romper la alianza bipartidista y forzar cambios", ahora les resulta más favorable pactar con el partido ganador porque reciben prebendas por apoyarlo y además, desempeñan un papel más importante que aquel que su fuerza política real les permitiría. Por su parte, los liberales, que si tenían la mayoría preferían votar solos o llegar a acuerdos con los conservadores, ahora acuden a las terceras fuerzas que les asegura "la capacidad de decidir cualquier votación, incluso las calificadas, lo que les asignaba un papel de cuasi-dictadores"62.

Aparte de permitirle aprobar su agenda, la construcción de amplios poderes partidistas lleva a que algunas de las reformas implementadas por la Constitución de 1991 se queden cortas para "moderar" el ejercicio del poder presidencial. Por ejemplo, si bien la delegación de la función legislativa fue objeto de importantes limitaciones, el ejecutivo continuó recibiendo tal delegación porque la dinámica transaccional le facilitaba conseguir del congreso la aprobación de leyes de facultades extraordinarias. Aunque es cierto que en este período hay una disminución

\footnotetext{
60 Duque (2015), pp. 107-111. Durante el mandato de Cesar Gaviria se volvió famoso el computador del ministro de gobierno Fabio Villegas en el que estaba detallada "la milimetría política". También Ernesto Samper se libró de la acusación de la Cámara negociando prebendas con cada congresista. Por último, Andrés Pastrana, que subió a la presidencia con una fuerte campaña anticlientelista, formó su coalición en el congreso repartiendo puestos. Ver: Medellín (2006), p. 231.

61 GutiérRez (1998).

62 Gutiérrez (1998), p. 245.
} 
considerable de la actividad legislativa ejercida por el ejecutivo respecto al período anterior, estas delegaciones le permiten encontrar una salida a las limitaciones que de forma reiterada le impuso la Corte Constitucional para recurrir a los estados de excepción. Es por esto por lo que en este período el ejercicio de la función legislativa por parte del presidente es muestra de unos fuertes poderes partidistas más que de una regulación permisiva por parte de la Constitución ${ }^{63}$.

Los poderes partidistas también hicieron que herramientas como la moción de censura se quedaran cortas para ejercer un control al ejecutivo. De hecho, los once intentos de moción de censura que se registran en este período fueron fallidos. Sobre el rechazo de las mociones presentadas por el congreso, no sólo influyó el grado de dificultad que supone cumplir con los requisitos que exige la Constitución para su aprobación (la mayoría absoluta de los integrantes de cada cámara $\left.{ }^{64}\right)$, sino sobre todo las mayorías que respaldaron en el congreso a cada uno de los presidentes y por consiguiente a sus ministros ${ }^{65}$. Por último, la construcción de amplios poderes partidistas permitió al presidente Ernesto Samper conseguir de la Cámara de Representantes una resolución de preclusión por la investigación que se adelantaba en su contra por el supuesto ingreso de dineros del narcotráfico a su campaña presidencial. A través de negociaciones individuales con congresistas, el presidente logró escapar al juicio político y evitó ser removido de su cargo ${ }^{66}$.

En este período se registra entonces una primera mutación del presidencialismo en la cual el ejecutivo, enfrentado a límites constitucionales que en algunos casos gracias la intervención de la Corte no consigue sobrepasar, encuentra en las prácticas tradicionales del clientelismo una herramienta para negociar individualmente con los congresistas y asegurarse el respaldo del congreso, respaldo que en el período anterior había conseguido a partir de la "convivencia burocrática"67. De la Constitución de 1991, pero sobre todo, de la capacidad del ejecutivo de

\footnotetext{
63 La mayor parte de los decretos que expide el ejecutivo durante este período continúa respondiendo a una delegación expresa que hace el congreso de su función legislativa. Si a partir de ésta, el ejecutivo expide 317 decretos, con las facultades que le otorgan los estados de excepción, expide tan solo 136. Ver: Arango Restrepo (2017).

64 En 2007, el Acto Legislativo 01 flexibilizó esta mayoría reduciéndola a la mayoría absoluta de la Cámara que la propone y no ya del congreso en pleno.

65 Duque (2015), pp. 70 y 71.

66 Comisión Ciudadana de Seguimiento (1996), p. 33.

67 Leal y Dávila (1990), pp. 55-57.
} 
resistirse a los cambios institucionales, resulta una nueva modalidad de hiperpresidencialismo que se construye ya no sobre un exceso de facultades legislativas, porque éstas se han moderado, sino sobre unos amplios poderes partidistas que le permiten al presidente concentrar poderes y ejercer un fuerte control sobre el congreso. Así, el ejecutivo se adapta a los cambios institucionales pero busca nuevas brechas en el sistema que le permiten continuar imponiéndose sobre el parlamento.

\section{Segunda Mutación del Sistema PRESIDENCIAL:}

LA REFORMA POLÍTICA DE 2003 (TERCER PERÍODO: 2002-2018)68

En este período el presidente conserva las facultades para intervenir en el proceso de creación de la ley establecidas en la Constitución de 1991. Esto quiere decir que el presidente tiene unas facultades limitadas para recurrir a los estados de excepción que se traducen, en la primera parte del período, en la continuación de la política del gobierno anterior de gobernar con las herramientas propias a un estado de normalidad. También la delegación de facultades extraordinarias para legislar se redujo de forma importante y la mayor parte de estas facultades las solicitó el ejecutivo al inicio del mandato para cumplir con su promesa de campaña de simplificar el Estado y acabar con la politiquería y la corrupción. Además de tener facultades legislativas moderadas, al inicio de este período los poderes partidistas del presidente son bastante débiles ya que para el primer mandato de Álvaro Uribe tanto las elecciones legislativas como las presidenciales se llevaron a cabo bajo las reglas electorales diseñadas por la Constitución de 1991, de manera que el congreso que lo acompaña se caracteriza por una gran "atomización"69 que permite que distintas fuerzas políticas consigan representación sin que ninguna de ellas obtenga la mayoría. A esta fragmentación se suma que el presidente no tuvo en el congreso un partido propio pues, al no conseguir

\footnotetext{
68 Este último período comprende los dos mandatos consecutivos de Álvaro Uribe Vélez y de Juan Manuel Santos, de forma que empieza el 7 de agosto de 2002 y termina el 6 de agosto de 2018. Si bien los amplios pero no excesivos poderes partidistas que construye Álvaro Uribe durante la primera parte de su primer mandato hubieran permitido clasificarlo dentro del período anterior -máxime si se tiene en cuenta que para éste, tanto el presidente como el congreso fueron elegidos con las reglas electorales de la Constitución de 1991- se prefirió estudiar ambos mandatos como un todo, de manera que puedan identificarse los excesos que adquiere el poder presidencial en su segundo mandato como el resultado de una serie de factores encadenados y no como un cambio repentino o abrupto.
}

69 Pizarro (2012). 
imponerse en la consulta interna del partido Liberal, Álvaro Uribe había lanzado su candidatura por el movimiento ciudadano "Primero Colombia" que no tenía representación parlamentaria ${ }^{70}$.

En principio podría pensarse que la reducción de las facultades legislativas impuesta por la Constitución de 1991 acompañada de unos débiles poderes partidistas que resultan de un congreso altamente fragmentado y la ausencia de un partido propio, son suficientes para minar el hiperpresidencialismo. Pero, si bien las condiciones institucionales son favorables para producir un desplazamiento hacia un presidencialismo "moderado", de nuevo no debe pasarse por alto la gran capacidad que tiene éste de mutar y de adaptarse a las nuevas reglas de juego. En efecto, la debilidad de estos poderes partidistas que se traducen al inicio de su mandato en un bloqueo de su agenda ${ }^{71}$, es superada con la dinámica transaccional que había servido a los gobiernos anteriores para conseguir la aprobación de sus promesas de campaña en el congreso. Este punto de quiebre es identificado por Medellín como "el fin de una presidencia ajena a las presiones y la intermediación clientelista de los congresistas y el comienzo de un matrimonio de convivencia entre el Poder Ejecutivo y el Legislativo, que levantaba un gran muro de contención a cualquier intento de transformar las costumbres políticas en el país"72. Para conseguir la aprobación de una reforma contra la politiquería, continúa el autor, el presidente se vio obligado a recurrir a prácticas politiqueras ${ }^{73}$.

A la utilización de esta herramienta "transaccional" se suma el crecimiento de los partidos afines al gobierno gracias al levantamiento de la prohibición del transfuguismo político que permitió a los congresistas cambiarse de partido por una sola vez sin ser sancionados. Esta figura fue incluida, por iniciativa del gobierno, en la reforma al sistema electoral y de partidos que adelantó el congreso

\footnotetext{
70 Esto no quiere decir que la victoria de su candidatura no hubiera dependido en gran medida del apoyo de distintas facciones de los partidos Liberal y Conservador. Éstas recibieron posiciones en el gobierno y sirvieron en el parlamento para formar una coalición que le permitiría al presidente aprobar gran parte de su agenda legislativa. Ver: DuQue (2012), p. 88.

71 Una de estas promesas fue la de poner fin a la politiquería y la corrupción y que el presidente intentó conseguir presentando al congreso una ley que convocaría a los ciudadanos a un referendo.

72 Medellín (2012), p. 222.

73 Estas prácticas "politiqueras" se refieren a la utilización del proyecto de ley sobre estímulos electorales, que estaba en curso, para incluir nuevos estímulos que tenían por objeto aumentar la participación en la votación del referendo y a la fijación de la votación para el mismo día en que se llevarían a cabo las elecciones locales (expresamente prohibida por la Constitución) y que se creía, aseguraría una alta participación.
} 
en 2003 con el fin de reducir la excesiva fragmentación y crear partidos más fuertes que dotaran a sus líderes de herramientas para conseguir la disciplina de sus miembros ${ }^{74}$. Si bien esta reforma política sólo empezó a regir a partir de las elecciones de 2006, el levantamiento de la prohibición de transfuguismo se aplicó en 2003, de forma que el presidente pudo conseguir durante su segundo año de mandato el apoyo de una coalición multipartidista que comprendía el sesenta por ciento del parlamento ${ }^{75}$.

La consecución de un amplio apoyo en el congreso facilitó al gobierno en el año 2004 conseguir la aprobación de una reforma constitucional que le permitiría levantar la prohibición de la reelección consecutiva del presidente de la República y extender su mandato. La aprobación de esta reforma, que se puso en duda durante el tercer debate en el congreso $^{76}$, fue garantizada a partir de las prebendas que otorgó el gobierno a dos representantes a la Cámara ${ }^{77}$. Con la posibilidad de reelegirse y siendo efectivamente reelegido, el poder del ejecutivo se multiplicó, no sólo porque se amplió su poder nominador sino además porque los órganos en cuya formación participó en su anterior mandato son los mismos que estaban llamados a ejercer un control durante su segundo período y en este sentido, estaban menos dispuestos a ejercerlo ${ }^{78}$.

\footnotetext{
74 El Acto Legislativo cambió la fórmula electoral -del método de Hare al de Hont-, creó el voto preferente según decisión de cada partido, exigió a los partidos que su organización interna fuera democrática y se les dotó de herramientas para controlar y cohesionar a sus miembros prohibiendo la presentación de múltiples listas, creó un umbral electoral, prohibió la doble militancia y dio la posibilidad, de manera transitoria, de que los congresistas pudieran formar nuevos partidos políticos siempre que sus votaciones sumaran, para las elecciones de 2002, el 2\% del total de votos válidos para Senado.

75 Duque (2015), p. 64.

76 El 1 de junio de 2004, 18 representantes pertenecientes a la Comisión Primera de la Cámara que darían tercer debate al proyecto, firmaron un documento en el que proponían su archivo. Compuesta la Comisión por 35 representantes, estos 18 constituían mayoría suficiente para conseguir el archivo del proyecto.

77 En varios procesos judiciales quedó probado que el ejecutivo, a través de los ministros del Interior y de Justicia (Sabas Pretelt de la Vega) y de Protección Social (Diego Palacio) habían otorgado prebendas a dos congresistas de la oposición (Yidis Medina y Teodolindo Avendaño) para conseguir en el tercer debate en la Comisión Primera de la Cámara de Representantes la aprobación del Acto Legislativo que autorizó la reelección consecutiva del presidente de la República. Ver: Corte Suprema de Justicia de Colombia, sentencia de 26 de junio de 2008, Proceso No 22453, sentencia de 3 de junio de 2009, Proceso 29705, Acta No 161 y sentencia de 15 de abril de 2015, Acta No 131 de la Sala de Casación Penal de la Corte Suprema de Justicia.
}

78 Corte Constitucional de Colombia, sentencia C-141 de 2010. 
En efecto, el presidente nombraba directamente dos miembros de la Comisión Nacional de Televisión ${ }^{79}$ y cinco de la Junta Directiva del Banco de la República. Además, intervenía en la conformación de distintos órganos proponiendo candidatos para su elección como, un candidato de la terna para elegir al Procurador General de la Nación; la terna para elegir al Defensor del Pueblo, al Fiscal General de la Nación y a los siete magistrados de la Sala Disciplinaria del Consejo Superior de la Judicatura y, la terna para elegir tres magistrados de la Corte Constitucional. Entre las instituciones que gracias a la reelección efectivamente tuvieron un mayor interferencia del ejecutivo están el Consejo Superior de la Judicatura y el Banco de la República. El primero, encargado de garantizar la autonomía de la rama judicial, tenía para el año 2008 a la totalidad de los magistrados de su Sala Disciplinaria nombrados por Álvaro Uribe. El segundo, tenía seis de un total de siete miembros, nombrados por el presidente, cuatro durante su primera administración y dos más en $2008^{80}$. Respecto a la Corte Constitucional, si durante su primer mandato el presidente no podía proponer las tres ternas para elegir magistrados porque la Constitución había previsto que sus períodos no coincidieran, durante los dos mandatos pudo ternar a los tres magistrados que tienen origen en el presidente. También Juan Manuel Santos se benefició de esta reforma que consideraba "inadecuada" pero que le permitió extender su mandato, ampliar su poder nominador e incidir sobre los órganos que estaban llamados a ejercer un control sobre él.

A medida que avanza el período el presidente va ampliando sus poderes partidistas. En efecto, el congreso que acompaña el segundo mandato de Álvaro Uribe y los dos mandatos de Juan Manuel Santos, es elegido mediante el sistema electoral creado por el Acto Legislativo 01 de 2003 y los partidos que forman la coalición de gobierno consiguen una mayoría holgada. La nueva fórmula electoral, junto a factores como la prohibición de las listas múltiples y la creación de umbrales, obligó a los partidos y movimientos a unirse bajo una misma etiqueta partidista so pena de ser condenados a su desaparición produciendo el efecto de reducir la fragmentación del sistema de partidos ${ }^{81}$. La prohibición de la doble militancia, por su parte, supuso "una dinámica de escisiones y agregaciones" en la que los movimientos que se habían formado al interior de los partidos

\footnotetext{
79 En este caso no se produce un fortalecimiento de su poder pues, siendo su período de apenas dos años, fuera reelegido o no, el presidente siempre tendría la oportunidad de nombrarlos.

80 Botero et al., 2010, p. 60.

81 Botero et al., 2010, p. 55.
} 
tradicionales pero que de manera simultánea actuaban como grupos autónomos, debían decidir si crear partidos independientes o fundirse dentro de ellos ${ }^{82}$. Esta escisión o reagrupación puso fin a la estrategia de los partidos de dividirse para obtener más curules y ocupar una mejor posición en el congreso. Sumado a esto, el comportamiento del Congreso estuvo determinado por la expedición de la Ley de Bancadas en 2005 que obligó a los miembros de las corporaciones públicas elegidos por un mismo partido o movimiento político o ciudadano, a conformar bancadas y actuar a través de ellas. El objeto de esta norma era disciplinar a los partidos y movimientos para que actuaran en grupo y de forma coordinada de acuerdo con las decisiones que fueran adoptadas democráticamente en su interior ${ }^{83}$. Por primera vez entonces los partidos y movimientos son dotados de mecanismos para controlar a sus miembros pues en sus estatutos internos pueden contemplar sanciones graduales a quienes desobedezcan sus directrices que pueden ir hasta la expulsión del partido o la pérdida del derecho al voto por el resto del período para el cual se ha sido elegido.

Si algunos teóricos desconfían del éxito de las coaliciones en los sistemas presidenciales, el tercer período demuestra que no sólo es posible formar coaliciones estables en ellos, sino que las herramientas con que cuenta un presidente para construirlas puede terminar convirtiéndolas en un instrumento a favor del hiperpresidencialismo. Los poderes partidistas que construyen ambos presidentes y que van tornándose excesivos ${ }^{84}$ a partir del segundo mandato de Álvaro Uribe, permite que el ejecutivo recupere su facultad de intervenir sobre el proceso de creación de la ley ${ }^{85}$. A pesar de que el ejecutivo ya no impulsa en este período

\footnotetext{
82 DuQue, 2012.

83 Artículo 2 del Acto Legislativo 1 de 2003 que reforma el artículo 108 de la Constitución y capítulo 1 de la Ley No 974 de 2005 que reglamenta el Régimen de bancadas.

84 Conviene advertir que el hecho de haber conseguido mayorías "aplastantes" no hizo que para el ejecutivo fuera siempre fácil imponer su agenda. Durante todo este período las prebendas se distribuyeron en gran medida entre miembros de la propia coalición de gobierno. De hecho, su bancada se negaba a apoyarlo de forma incondicional y tanto Álvaro Uribe con Juan Manuel Santos tuvieron que afrontar "varias rebeliones" que descompletaban sus mayorías. Ver: GuTIÉRREZ (2006), p. 120). El ejecutivo construye así una mayoría siempre y cuando revalide esos apoyos a la hora de la votación, apoyos que dependen de "asignar y distribuir cuotas en la burocracia estatal, en los cargos diplomáticos y en esferas de influencia del poder ejecutivo". Ver: DuQue (2011), pp. 449 y 450.

85 Durante el gobierno de Santos, el uribismo filtró el contenido del computador de palacio donde constaban los cupos indicativos que se habían repartido por congresista a cambio de que se votaran los proyectos propuestos por el gobierno.
} 
su agenda de forma unilateral a través de la expedición de decretos ${ }^{86}$, el control de una mayoría en el congreso le permite obtener de él la aprobación de los proyectos de iniciativa gubernamental -incluso de aquellos que encontraban una fuerte resistencia en la opinión pública ${ }^{87}$-, la aceptación de los vetos a los proyectos que no convienen al gobierno, la recepción de los mensajes de urgencia y el rechazo a todas las mociones de censura que se promueven en contra de sus ministros. Y aunque la creación de la ley en el parlamento sigue estando sometida a un proceso de discusión que supone la inclusión de modificaciones, los controles de la oposición y, en ocasiones, la movilización de la opinión pública, también es cierto que cuando el control que ejerce el ejecutivo alcanza un nivel determinado, esta mayoría se revela "aplastante" y la discusión puede resultar insignificante porque las decisiones vienen dadas desde arriba. A diferencia del resto de períodos, en la primera parte de este período el carisma del presidente y los altos índices de favorabilidad que obtiene su gestión entre los ciudadanos, dotan al hiperpresidencialismo de características particulares. La identificación de los ciudadanos con el carisma del líder y no con el programa ideológico de un partido político determinado, hizo recurrente que durante su mandato éste apelara a su legitimidad democrática para imponerse a las directivas de cualquiera de los partidos que lo apoyaban y que afectaba la disposición de los demás poderes a ejercer un control sobre sus decisiones ${ }^{88}$.

\footnotetext{
86 Respecto a las facultades extraordinarias, el presidente solicitó al congreso menos delegaciones para ejercer la función legislativa en la totalidad de este período. La mayor parte de estas facultades las solicitaron ambos presidentes al inicio de su mandato, Álvaro Uribe para cumplir con su promesa de campaña de simplificar el estado y acabar con la politiquería y la corrupción y Juan Manuel Santos para revertirlas. En ambos casos, la reducción de los decretos extraordinarios puede explicarse en las coaliciones que forman ambos presidentes que les permite que el congreso apruebe su agenda sin que sea necesario impulsarla de forma unilateral mediante decreto. Ver: ArANGo Restrepo (2017).

87 Dentro de los proyectos más polémicos, Álvaro Uribe aprobó a través de su coalición reformas como el Estatuto Antiterrorista y la modificación de la ley que convocaba a un referendo para permitir una segunda reelección consecutiva del presidente de la República. La coalición de Santos, por su parte, que incluso fue mayor a la de su predecesor y que por su tamaño fue llamada la "aplanadora", consiguió la aprobación de una reforma a la justicia en 2012 y la ratificación por el congreso de los acuerdos de paz firmados por el gobierno y las FARC.

88 Además del carisma del presidente y los altos índices de favorabilidad que obtiene su gestión entre los ciudadanos, el hiperpresidencialismo que se configura durante los dos mandatos de Álvaro Uribe tiene una particularidad que Medellín denomina "el régimen de la presidencia personal". Ver: MedelLín (2006, p. 240). En éste el presidente empieza a desempeñar funciones que son propias de los ministros y a desplazarlos en la toma de las decisiones que les competen. Como ejemplos, el autor se refiere a la discusión directa del presidente con los congresistas, a la negociación con sindicatos, y tal vez la más importante, la
} 
Si bien entonces se pensó que la reforma política de 2003 facilitaría la construcción de partidos más fuertes que permitirían al congreso ejercer un contrapeso efectivo sobre el ejecutivo, nuevamente se pasó por alto la gran capacidad de mutar que el presidencialismo ha desarrollado para conseguir que el ejecutivo continúe concentrando poderes. No obstante, a diferencia del período anterior, en éste el ejecutivo no se conforma con buscar nuevas brechas en el sistema que le permitan aumentar su poder sino que interviene directamente para conseguir que el congreso apruebe una reforma a la Constitución que destrabara los controles que estaban llamados a ejercer sobre él las demás instituciones. De esta forma, varios de los cercos institucionales que intentaban contener el poder presidencial se derrumban y el presidente logra recuperar el poder que la Constitución de 1991 había minado. El segundo intento de los partidos afines al gobierno de Álvaro Uribe de promover una reforma que avalara la reelección consecutiva del presidente de la República por segunda vez, esto es, que ampliara su período a doce años, es otra muestra de la intervención del propio ejecutivo para modificar las reglas de juego a su favor.

\section{CONCLUSIÓN}

En el período comprendido entre 1974 y 2018 se registran profundas transformaciones en el ejercicio del poder presidencial que responden, en principio, a reformas constitucionales, pero en cuyo resultado convergen las decisiones y prácticas de múltiples actores políticos. Pese a las reformas constitucionales implementadas, las variaciones que experimenta el poder presidencial entre 1974 y 2018 no permiten desplazar el sistema hacia modalidades distintas al hiperpresidencialismo. Sea por un exceso de facultades legislativas o de poderes partidistas, el sistema presidencial colombiano encaja en la categoría de "hiper” durante los tres períodos, de forma que el ejecutivo continúa ocupando una posición preponderante que le permite tomar las decisiones políticas más

utilización de la figura de los Consejos Comunitarios. A través de éstos, advierte Medellín, el presidente buscó relacionarse directamente con los ciudadanos obviando el papel de intermediación que están llamados a ejercer los congresistas y los partidos políticos. El presidente empieza a intervenir y a tomar decisiones en los asuntos locales, saltándose los procedimientos y autoridades establecidos para ello. Así mismo, señala Medellín, "el presidente empezó a romper las jerarquías institucionales y a consultar directamente a los mandos medios, de forma que el problema ya no es sólo la excesiva concentración del poder presidencial sino además su dispersión en los mandos medios” MedelLín (2006), pp. 246 y 247. 
importantes, invadiendo e incluso en ocasiones anulando, las competencias y contrapesos ejercidos por las demás ramas e instituciones.

No obstante, y este es un segundo hallazgo importante, no se trata de una misma forma de hiperpresidencialismo. Una mirada atenta a las reformas que se diseñaron para restablecer el equilibrio de poderes a lo largo de estos cuarenta años, permitió identificar claramente en cada uno de los períodos, una modalidad distinta de hiperpresidencialismo. En efecto, en el primero, el hiperpresidencialismo se construye sobre un exceso de facultades legislativas y unos amplios, aunque no excesivos, poderes partidistas, que le permiten al ejecutivo imponer sus decisiones al congreso. Recortadas las facultades legislativas con la Constitución de 1991 y con poderes partidistas reducidos, el ejecutivo recurre a herramientas transaccionales que le permiten compensar la pérdida de poder que supuso la nueva Carta y la insistencia de la Corte de que no podía recurrir a los estados de excepción para gobernar. Así, el hiperpresidencialismo del segundo período se construye, no ya sobre un exceso de facultades legislativas porque éstas se han moderado sino, sobre unos amplios poderes partidistas de los que se sirve el presidente para impulsar su agenda de gobierno y evadir los controles que sobre él está llamado a ejercer el congreso. Por último, el hiperpresidencialismo que se configura en el tercer período, se construye sobre facultades legislativas moderadas, que se van ampliando de forma progresiva, $y$ amplios poderes partidistas que devienen excesivos. Si bien los efectos de cada una de estas formas de hiperpresidencialismo no fueron estudiados este artículo, conviene advertir que dependiendo del pilar en el que se apoye el ejecutivo para concentrar poderes, su actuación tendrá repercusiones sobre distintas facetas de la democracia.

Ahora bien, la transformación que experimenta el sistema presidencial colombiano entre 1974 y 2018, no sólo confirma la fuerte tendencia que tiene el presidencialismo a concentrar poderes en cabeza del ejecutivo sino que además evidencia que una vez éste se encuentra en la categoría de "hiper", desarrolla una gran capacidad de mutar que le permite adaptarse a las reformas que intentan restablecer un equilibrio entre los poderes públicos para evitar que el ejecutivo pierda su supremacía dentro del sistema. Este fenómeno ha hecho posible en el caso colombiano que cada vez que una reforma constitucional reduce los poderes legislativos o partidistas del ejecutivo, éste se adapte formalmente a estos límites -en ocasiones, gracias a la presión que sobre él han ejercido instituciones como la Corte Constitucional- pero que busque nuevas brechas en el sistema que le permiten evadir controles e imponer sus decisiones al congreso. Esta capacidad 
de mutar ha probado que la estrategia de recurrir a las reformas institucionales para contener los efectos que tiene sobre la democracia el desbordamiento del poder presidencial, ha sido insuficiente para moderar sus excesos y revertir las tendencias autoritarias del sistema. Se han equivocado en el diagnóstico del problema quienes han entendido que para moderar el hiperpresidencialismo basta con impulsar reformas institucionales destinadas a recortar las facultades y poderes partidistas del presidente o a ampliar los controles de la rama judicial. Han obviado la fuerza que tienen las prácticas políticas para resistir a las reformas institucionales y sacar partido de situaciones que en principio pueden resultar desfavorables.

Para concluir, esta capacidad de mutar sugiere que el hiperpresidencialismo no sólo es resultado de un diseño institucional sino también de las prácticas políticas. El problema que plantea entonces no parece ser exclusivamente un problema de excesivas facultades otorgadas por la Constitución al ejecutivo, de ausencia de controles o de tergiversación del principio de separación de poderes que pueda corregirse a partir de controles "adecuados" o de una ampliación de la participación de la ciudadanía. El hiperpresidencialismo se construye sobre unas prácticas y, por tanto, sobre una manera de hacer política. El pasado autoritario sobre el que se asienta el presidencialismo latinoamericano sigue determinando la dirección de estos regímenes y el comportamiento de sus instituciones. Es por esto que las dinámicas políticas que guían este comportamiento no sólo discurren por cauces distintos a los trazados por las reformas institucionales sino que actúan en contracorriente, resisten a sus presiones e incluso consiguen ganar el pulso.

\section{BibLIOGRAFÍA}

Arango Restrepo, Ana Catalina (2017): Mutaciones del presidencialismo: la transformación del poder presidencial en Colombia (1974-2010) [tesis doctoral inédita], Universidad Carlos III de Madrid.

(2018): "Presidencialismo", Eunomía. Revista en Cultura de la Legalidad, No 14, abril-septiembre 2018, pp. 244-261.

Archer, Ronald (1995): "Party Strength and Weakness in Colombia's Besieged Democracy", en Mainwaring, Scott y Scully, Timothy (eds.), Building Democratic Institutions: Party Systems in Latin America (Stanford, Stanford University Press), pp. 164-199. 
Archer, Ronald y Chernick, Marc (1989): "El presidente frente a las instituciones nacionales", en Vásquez Urrutia, Patricia (edit.), La democracia en blanco y negro: Colombia en los años ochenta (Bogotá, Uniandes), pp. 31-79. Archer, Ronald y Shugart, Matthew Soberg (1997): “The Unrealized Potential of Presidential Dominance in Colombia”, en Mainwaring, Scott y Shugart, Matthew Soberg (edit.), Presidentialism and Democracy in Latin America (Cambridge, Cambridge University Press), pp. 110- 159.

Ariza, Libardo y BARreto, Antonio (2001): "La Corte Constitucional frente a la excepcionalidad: diez años de control material laxo y discursivo", Derecho Constitucional. Perspectivas criticas. Observatorio de Justicia Constitucional, (Bogotá, Universidad de los Andes), pp. 137-171.

Barreto Rozo, Antonio (2012): "La generación del Estado de sitio: el juicio a la anormalidad institucional colombiana en la Asamblea Nacional Constituyente de 1991", Precedente. Revista Jurídica, Vol. 1, pp. 9-48.

Bejarano, Ana María y Pizarro, Eduardo (2005): "From $<$ Restricted $>$ to $<$ Besieged $>$ : The Changing Nature of the Limits to Democracy in Colombia", en Hagopian, Frances y Mainwaring, Scott (eds.), The Third Wave of Democratization in Latin America: Advances and Setbacks (Cambridge, Cambridge University Press), pp. 235-260.

Botero, Felipe et al. (2010): "Sobre forma y sustancia: una evaluación de la democracia electoral en Colombia", Revista de Ciencia Política, Vol. 30. No 1, pp. 41-64.

Comisión Ciudadana de Seguimiento (1996): Poder, Justicia e Indignidad: El Juicio al Presidente de la República Ernesto Samper Pizano (Bogotá, Editorial Buena Semilla).

Dix, Robert (1987): The Politics of Colombia (Praeger, New York).

DuQue DazA, Javier (2011): "Redefinición de las reglas de juego. Las reformas al sistema electoral colombiano como un caso de volatilidad institucional, 1991-2011", Papel Político, Vol. 16, No 2, pp. 421-460.

(2012): "Las elecciones presidenciales de 2006 en Colombia: cambio institucional, nueva configuración partidista y reelección”, en LOPEZ LEYvA, Miguel Armando et. al (coords.), La democracia en México y América Latina: claves de lectura (México, Instituto de Investigaciones Sociales), pp. 67-115. (2014): “¿Presidentes legislando? Las facultades legislativas en el presidencialismo colombiano 1991-2014”, Estudios Socio-Jurídicos, Vol. 17, No 1, pp. 77-123. 
(2015): "La moción de censura en Colombia. Reglas, coaliciones e intentos fallidos", Colombia Internacional, Vol. 83, pp. 43-75.

García Montero, Mercedes (2009): Presidentes y parlamentos: ¿quién controla la actividad Legislativa en América Latina? (Madrid, Centro de Investigaciones Sociológicas).

García Villegas, Mauricio (2001): "Constitucionalismo perverso. Normalidad y anormalidad constitucional en Colombia (1957-1997)", en Santos y García Villegas (dirs.), El caleidoscopio de las justicias en Colombia (Bogotá, UniandesSiglo del Hombre-Colciencias-CES, Tomo I), pp. 317-370.

García Villegas, Mauricio y Uprimny, Rodrigo (2005): “¿Controlando la excepcionalidad permanente en Colombia? Una defensa prudente del control judicial de los estados de excepción", en Documentos de Discusión de "DJS", Documento No 1. Disponible en: http://www.dejusticia.org/files/r2_actividades_recursos/fi_name_recurso.198.pdf. Revisado el 30 de marzo de 2019. Gargarella, Roberto y Courtis, Christian (2009): "El nuevo constitucionalismo latinoamericano: promesas e interrogantes”, CEPAL, Serie Políticas Sociales No 153.

Gutiérrez Sanín, Francisco (1998): "Rescate por un elefante. Congreso, sistema y reforma política”, en Bejarano, Ana María y Dávila, Andrés (comp.), Elecciones y Democracia en Colombia, 1997-1998 (Bogotá, Departamento de Ciencia Política Universidad de los Andes -Fundación Social -Veeduría Ciudadana a la Elección Presidencial), pp. 215-253.

(2006): "Estrenando sistema de partidos", Análisis Político, Vol. 19, No 57, pp. 106-125.

Hoskin, Gary (1988): "Colombian Political Parties and Electoral Behavior during the Post-National Front period”, en Herman, D (ed.), Democracy in Latin America: Colombia and Venezuela (Praeger, New York), pp. 47-62.

Leal Buitrago, Francisco y Ladrón de Guevara, Andrés Dávila (1990): Clientelismo: el sistema político y su expresión regional (Bogotá, Tercer Mundo Editores).

LIJPHART, Arend (2000): Modelos de democracia: formas de gobierno y resultados en 36 paises (Barcelona, Ariel, 2012).

LinZ, Juan José (1978): La quiebra de las democracias, Traducción de Rocío de Terán (Madrid, Alianza Editorial, 1996). 
Loewenstein, Karl (1949): "The Presidency Outside the United States: A Study in Comparative Political Institutions", Journal of Politics, Vol. 11, No 3 , pp. 447-496.

Mainwaring, Scott y Shugart, Matthew (1997): "Juan Linz, Presidentialism and Democracy: a critical appraisal”, Comparative Politics, Vol. 29, No 4, pp. 449-471.

Marsteintredet, Leiv (2008): "Las consecuencias sobre el régimen de las interrupciones presidenciales en América Latina”, América Latina Hoy, Vol. 49, pp. 31-50.

Medellín Torres, Pedro (2006): El presidente sitiado: ingobernabilidad y erosión del poder presidencial en Colombia (Bogotá, Planeta).

Nino, Carlos Santiago (1990): "El presidencialismo y la justificación, estabilidad y eficiencia de la democracia", Propuesta y control, pp. 39-56.

PéCAut, Daniel (1989): Crónica de dos décadas de política colombiana: 1968-1988 (Bogotá, segunda edición, Siglo XXI Editores).

PÉREZ LiÑÁn, Aníbal (2000): “¿Juicio político o golpe legislativo? Sobre las crisis constitucionales en los años noventa", América Latina Hoy, No 26, pp. 67-74.

Pizarro Leongómez, Eduardo (1997): “¿Hacia un sistema multipartidista? Las terceras fuerzas en Colombia hoy”, Análisis político, No 31, pp. 85-108.

(2002): "La atomización partidista en Colombia: el fenómeno de las microempresas electorales", en Gutiérrez Sanín, Francisco (Comp.), Degradación o cambio. Evolución del sistema político colombiano (Bogotá, Editorial Norma), pp. 357-401.

SÁcHICA, Luis Carlos (1970): La reforma constitucional de 1968 (Bogotá, Editorial Temis).

Shugart, Matthew Soberg y Carey, John (1992). Presidents and Assemblies: Constitutional Design and Electoral Dynamic (Cambridge, Cambridge University Press).

UNGAR Bleier, Elizabeth y Ruiz, Germán (1998): “¡Hacia una recuperación del Congreso?”, en Bejarano, Ana María y Dávila, Andrés (comp.), Elecciones y Democracia en Colombia, 1997-1998 (Bogotá, Departamento de Ciencia Política Universidad de los Andes - Fundación Social - Veeduría Ciudadana a la Elección Presidencial), pp. 191-214.

Uribe Vargas, Diego (1977): Las constituciones de Colombia (Madrid, Segunda edición, 3 vols., Ediciones Cultura Hispánica, 1985). 
VÁzquez Carrizosa, Alfredo (1986): El poder presidencial en Colombia: la crisis permanente del derecho constitucional (Bogotá, Ediciones Suramérica).

WILDE, Alexander (1982): Conversaciones de caballeros. La quiebra de la democracia en Colombia (Bogotá, Ediciones Tercer Mundo).

YePes ARCILA, Hernando (1974): La reforma constitucional de 1968 y el régimen político colombiano (Manizales, Imprenta Departamental de Caldas). 